\title{
Comparing Perceived Social Support and Perceived Stress in Healthy Pregnant Women and Pregnant Women with Preeclampsia
}

\author{
Sarmasti $\mathbf{N}^{1}$, Ayoubi $\mathrm{SH}^{2}$, Mahmoudi $\mathrm{G}^{3}$, Heydarpour $\mathrm{S}^{4 *}$
}

\footnotetext{
OPEN ACCESS

Citation: Sarmasti N, Ayoubi SH, Mahmoudi G, Heydarpour S. Comparing Perceived Social Support and Perceived Stress in Healthy Pregnant Women and Pregnant Women with Preeclampsia. Ethiop J Health Sci. 2019;29(3):369.

doi:http://dx.doi.org/10.4314/ ejhs.v29i3.9

Received: February 12, 2019

Accepted: April 4, 2019

Published: May 1, 2019

Copyright: (C) Sarmasti, N. et al. This is an open access article distributed under the terms of the Creative Commons Attribution License, which permits unrestricted use, distribution, and reproduction in any medium, provided the original author and source are credited.

Funding: Nil

Competing Interests: The authors declare that this manuscript was approved by all authors in its form and that no competing interest exists.

Affiliation and Correspondence:

${ }^{1}$ Department of Psychology and

Consultation, Faculty of Literature and

Humanities, Islamic Azad University

Kermanshah Branch, Kermanshah,

Iran

${ }^{2}$ Department of Psychology and

Consultation, Faculty of Literature and Humanities, Islamic Azad

3Department of Psychology and Consultation, Faculty of Literature and Humanities, Islamic Azad University Kermanshah Branch, Kermanshah, Iran

${ }^{4} \mathrm{PhD}$ of Reproductive health, Department of Midwifery, Faculty of Nursing and Midwifery, Kermanshah University of Medical Sciences, Kermanshah, Iran

University Kermanshah Branch, Kermanshah, Iran

*Email: s.heydarpour1394@yahoo.com
}

\author{
ABSTRACT
}

BACKGROUND: Preeclampsia is a prevalent side effect of pregnancy. Different studies have reported different results about the relationship between mental stress and blood pressure disorders. In addition, social support is highly important to help women who experience risky pregnancy in adapting to the stressors they experience. This study aimed to compare perceived social support and perceived stress in women with and without preeclampsia.

METHODS AND MATERIALS: Fifty pregnant women definitely diagnosed with preeclampsia and 50 healthy pregnant women visiting public hospitals including Hazrat Masoumeh, Motazedi, and Imam Reza in Kermanshah-Iran took part in a descriptiveanalytical study from June 2017 to January 2018. Data gathering tools included demographics questionnaire, social support appraisals scale and perceived stress scale. The collected data was analyzed with SPSS (v.20) using independent t-test.

RESULTS: The mean score of perceived social support in the preeclampsia and non-preeclampsia groups were $69.88 \pm 7.3$ and $76.80 \pm 7.6$ respectively $(P<0.01)$. The mean score of perceived stress in the preeclampsia and non-preeclampsia groups were $35.6 \pm 8.7$ and $26.01 \pm 5.56$ respectively $(P<0.01)$. This means that compared with healthy women, women with preeclampsia perceived more stress and less social support.

CONCLUSION: In comparison with healthy pregnant women, women with preeclampsia perceived more stress and less social support. Healthcare providers should recommended to pay more attention to improving social support and attenuating stress in pregnant women.

KEYWORDS: Perceived social support, perceived stress, preeclampsia, pregnancy

INTRODUCTION Preeclampsia is a prevalent side effect of pregnancy. Pregnant women $(\mathrm{PW})$ may experience it after the $20^{\text {th }}$ week of pregnancy. It is characterized with high blood pressure (BP), proteinuria, and the like. Two out of every $10 \mathrm{PW}$ in the world experience the complication (1-5). Prevalences of the disease in Zabol and Hormozgan Province (in Iran) were reported as $6.5 \%$ and $5.8 \%$ respectively (6-7). 
Preeclampsia and eclampsia may create a variety of side effects for the mother and the fetus so that 50000 women die in the world annually due to the disease and its side effects (8). The disorder may be related to other pregnancy complications like preterm delivery, fetus development disorders, and placental abruption (9). Several studies have shown the relationship of pregnancy BP and chronic BP with cardiovascular diseases (CVDs), metabolic disease in future (10), thromboembolic, and death (11). Sixteen percent of the death rate in mothers in the developed countries is due to high BP. The death rate due to $\mathrm{BP}$ is higher than the death rate caused by bleeding (13\%), abortion (8\%), and sepsis $(2 \%)$ (9). Preeclampsia is the third top cause of death of mothers in the world and the second cause of death of mothers in Iran (12). Several risk factors have been found for the complication including general, genetics, midwifery, and medical risk factors. Acording to World Health Organization (WHO), mental-social condition including mental social stresses and Social support (SS) might affect one's health condition (13). Despite several studies in this area, the pathophysiology is not clear to us (14). Results obtained from the recent data about hyperactivity of sympathetic system in preeclampsia cases might be indicative of the role of spiritual, mental, autonomy nervous system stresses, and the central nervous system as the risk factors of preeclampsia (15). These are coincident with an increase incorticotropinreleasing hormone (CRH) secreted by the placenta and an increase in adrenocorticotropine and cortisol hormones in the blood flow of the mother and the placenta (16).

Perceived stress (PS) refers to one's inability to cope with stressful situation (17). Brinkley and Stark showed that there was a significant and negative relationship between PS and health promoting life style. There is also a significant negative relationship between PS and mental development and between inter-personal relationships and stress management (18).

Some studies have reported that there is a positive relationship between the mental aspects of pregnant mothers and preeclampsia (19-21) so that women with preeclampsia had higher stress score than mothers without preeclampsia (21-22). Leaners et al. (2007) found that the relationship between stress and increase in BP during pregnancy was statistically significant (23). Black (2007) reported that severe preeclampsia groups experienced a higher level of stress compared with mild preeclampsia groups (24). Several studies have listed perceived SS as a key preventive factor for mental and physical health (25- 26). SS during pregnancy is one of the factors in adaptation to motherhood role (27). People who enjoy a high level of SS are less vulnerable to diseases even if they experience new pressures and stressors (28).

Studies have shown that there is a positive relationship between the mental situation of PW and preeclampsia $(20,24,29)$. Increase in BP, increase in cardiac output, and increase in blood catecolamine level affect individual's physiological functions and health. On the other hand, the positive responses by the brain, which are probably due to supportive stimulators, attenuate high BP caused by traumatic incidents (30).

Due to the complications of preeclampsia for the mother and the baby and its unknown etiology. The importance of screening PW regarding the risk factors of this disease and the emphasis of the WHO on the relationship between psychosocial factors and diseases. This study was conducted to compare perceived SS and PS in women with and without preeclampsia in 2017. As long as a connection has been found it can be used to prevent and reduce the diseases in PW.

\section{MATERIALS AND METHODS}

Study setting and design: The authors visited Kermanshah-based public hospitals that had women clinics (HazaratMasoumeh, Motazedi, and Imam Reza). Fifty PW definitely diagnosed with preeclampsia and 50 healthy $\mathrm{PW}$ took part in this descriptive-analytical study, carried out from July 2017 to January 2018. Sampling was carried out through stratified-random method. Preeclampsia cases were diagnosed based on

DOI: http://dx.doi.org/10.4314/ejhs.v29i3.9 
preeclampsia diagnosis checklist and preeclampsia diagnosis measures after 20 weeks of pregnancy (systolic BP $\geq 140 \mathrm{mmHg}$, diastolic BP $\geq 90 \mathrm{mmHg}, \quad 24 \mathrm{hrs}$ proteinuria $=300 \mathrm{mg}$ or proteinuria $\geq+1$ in test tape method). The diagnosed cases were confirmed by a women specialist. BP was measured by the researcher for the right arm in sitting position.

Demographics and midwifery forms, the social support appraisal scale (SSA, Vaux) and PS scale (PSS-14, Cohen) were filled out by the researcher through interviewing the participants of both groups. In the case of control group, the questionnaire was filled out while participants were waiting for their prenatal visit or admittance to maternity ward or before child delivery. The inclusion criteria were age range of 18-35, Iranian nationality, first marriage, healthy singleton fetus, gestational age $>20$ weeks (based on the first day of the last menstrual period, LMP, or first trimester sonography), no chronic disease (e.g. antiphospholipid syndrome, cardiovascular, renal, pulmonary, thyroid, autoimmune, diabetes diseases), no pregnancy side effect (nausea, hyperemesis gravidarum, diabetes, hypertension, cardiovascular, renal, and pulmonary disease) and molar pregnancy, no drug addiction, no smoking habit, $\mathrm{BMI} \leq 29$, and no stressful incident over the past six months. The exclusion criteria were reluctance to continue participation in the study and using antihypertensive drugs in the control group.

Sampling techniques: Following Moafi et al. (2013), and assuming $\delta 1=4 / 42, \mu_{1}=18 / 8, \delta_{2}=3 / 32$, $\mu_{2}=16 / 09, \alpha=0 / 05$, and $\beta=0 / 1(20)$, the sample size was estimated to be 44. Taking into account probable leaves, 50 participants were selected for each group. At first, each hospital was considered as a stratum and then each stratum was allocated with a quota, and the required number of participants from each hospital were selected randomly.

Data collection:The data gathering tools included demographics questionnaire, SSA, and PSS-14. The demographics questionnaire consisted of items on age, education, job, and family income. With 23 statements, SS-A indicates the extent to which the individual feels respect and love from others and the extent of relationship with relatives, friends, and others (31-33). It contains three subscales of family (eight statements), friends (seven statements), and others (eight statements). The statements are four alternatives questions (very agree, agree, disagree, and very disagree). Questions 3, 10, 13, 21, and 22 are scored inversely. Total score is the sum of scores of questions 1 to 23, and score range is 23-92. The higher the score, the higher the perceived SS. In Iran, reliability and validity of this tool were examined by Ebrahimi-ghavam in 1992, and its Cronbach's alpha was reported from 0.70 to 0.90 (34).Cronbach's alpha of total SS scale and its subscales including family SS, friends SS and SS of others were reported $\alpha=0 / 83, \alpha=0 / 89, \alpha=$ $0 / 86$ and $\alpha=0 / 84$ respectively by Rashedi et al. (2013), in Iran (35). Also, Cronbach's alpha of SS-A was reported as 0.74 by Khabaz in Iran (36).

With 14 statements, PSS-14 is designed based on Likert's four-point scale (never,..., very high), and the score of each statement ranges from 0 to 4. Statements, 4, 5, 6, 7, 9, 10, 13 are scored inversely. The tool is comprised of two subscales of negative and positive perceptions of stress appraisal. The seven negative items indicate inability to resist stress and seven positive items indicate good adaptability with stressors. The minimum and maximum scores are 1 and 56 respectively. The higher the score, the lower the PS. To answer the statements, the respondent needs to express their opinion about uncontrollability, unpredictability, and excruciating nature of stress on their life over the past month (37-38). The tool was validated in Iran by Maroufizadeh et al. in 2014, and its Cronbach's alpha was 0.90 (39).

In this study, to control bias, stratified random sampling was used, a standard questionnaire was filled out by the researcher through interviewing the participants of both groups and variables as the inclusion criteria were controlled through group matching.

Data analysis: The collected data was analyzed with SPSS (v.20) using descriptive statistics (mean, standard deviation, plots, etc.) and inferential statistics (independent t-test). To ensure normal distribution of the data,

DOI: http://dx.doi.org/10.4314/ejhs.v29i3.9 
Kolmogorov Smirnov (KS) test was used, and Leven test was used to assess equality of variances.

Ethics: The study's code of ethics (19220705961021) was obtained from the Ethic Committee of Islamic Azad University. A letter of introduction from the Research Department of the university was received. Consent form was obtained from the participants. They had been briefed about the objectives of the study and assured that they could leave the study at any time. The participants were informed about the confidentiality of their information and assured that the data would be used only for research. Anonynity was also maintained.

\section{RESULTS}

Demographics of the participants of the both groups is listed in Table 1.

Table 1: Demographics of the participants

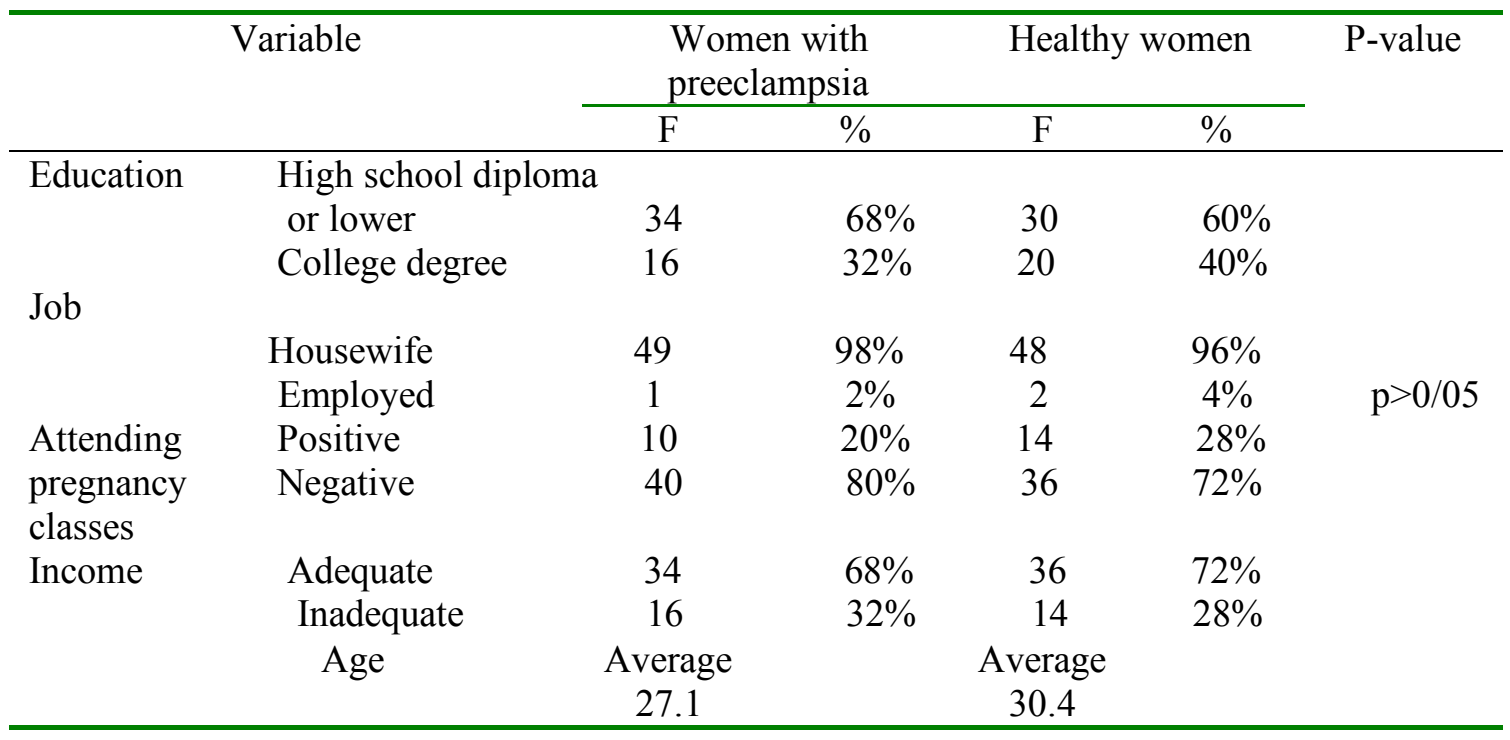

To compare mean scores of the two groups, independent t-test was used. Before performing the test, the prerequisites of the tests were checked. To examine normal distribution of the variables, KS test was used and normal distribution of the data was supported. This means that the parametric tests can be used for data analysis.

The results showed that the mean score and standard deviation of perceived SS by the healthy $\mathrm{PW}$ was $76.80 \pm 7.3$, which is relatively higher than that of the women with preeclampsia $(69.88$ \pm 7.3 ). As listed in Table 2, by assuming that the variances are equal, the information of the first row of the table can be used to assess equality of the mean scores of the two groups; otherwise, the information of the second row should be used. Given the information in the table, probability (pvalue) of equality of the variances based on Levene's test is $0.906>0.05$ (level of confidence $(\mathrm{LC})=95 \%$ ). Thus, the assumption of equality of variances is supported and information of the first row can be used to assess equality of mean scores of the two groups. Moreover, there is a significant difference between the mean scores of the two groups, which means that there is a significant difference between the two groups in terms of the perceived SS.

DOI: http://dx.doi.org/10.4314/ejhs.v29i3.9 
Table 2: Independent t-test on perceived social support by the participants

\begin{tabular}{cccccccc}
\hline & \multicolumn{2}{l}{$\begin{array}{l}\text { Levene test to examine } \\
\text { equality of variances }\end{array}$} & \multicolumn{5}{c}{ T-test to assess equality of mean scores } \\
\cline { 2 - 6 } & F value & Sig. & $\begin{array}{c}\text { T } \\
\text { value }\end{array}$ & DF & Sig. & $\begin{array}{c}\text { Differences of } \\
\text { mean scores }\end{array}$ & $\begin{array}{c}\text { SD of } \\
\text { differences }\end{array}$ \\
\cline { 2 - 6 } $\begin{array}{c}\text { Equality of } \\
\text { variances } \\
\begin{array}{c}\text { Inequality of } \\
\text { variances }\end{array}\end{array}$ & 0.014 & 0.906 & 2.39 & 98 & 0.04 & 6.92 & 2.12 \\
\hline
\end{tabular}

As the results showed, the mean score and SD of the PS in the healthy PW was $26.01 \pm 5.56$, which is relatively less than that of $\mathrm{PW}$ with preeclampsia (35.60土8.7). As listed in Table 3, by assuming that the variances are equal, the information of the first row of the table can be used to assess equality of the mean scores of the two groups; otherwise, the information of the second row should be used. Given the information in the table, probability (p-value) of equality of variances based on Levene test is $0.068>0.05$ (level of confidence $(\mathrm{LC})=95 \%$ ). Thus, the assumption of equality of variances is supported and the information of the first row can be used to assess equality of mean scores of the two groups. Moreover, the difference of the mean scores of the two groups is equal to 9.59 and the $\mathrm{p}$-value of t-test is $12 \%$. Therefore, the difference is significant. In other words, there is a significant difference between the two groups in terms of PS.

Table 3: Independent t-test on perceived stress by the participants

\begin{tabular}{cccccccc}
\hline & \multicolumn{2}{l}{$\begin{array}{l}\text { Levene test to examine } \\
\text { equality of variances }\end{array}$} & \multicolumn{5}{c}{ T-test to assess equality of mean scores } \\
\cline { 2 - 6 } & F value & Sig. & T & DF & Sig. & $\begin{array}{c}\text { Differences of } \\
\text { mean scores }\end{array}$ & $\begin{array}{c}\text { SD of } \\
\text { differences }\end{array}$ \\
\cline { 2 - 6 } & 5.02 & 0.068 & 1.680 & 98 & 0.012 & 9.59 & 2.06 \\
$\begin{array}{c}\text { Equality of } \\
\text { variances } \\
\begin{array}{c}\text { Inequality of } \\
\text { variances }\end{array}\end{array}$ & & 0.680 & 97.3 & 0.012 & 9.59 & 2.06 \\
\hline
\end{tabular}

\section{DISCUSSION}

There was a significant difference between the PW with and without preeclampsia in terms of all the subscales of SS. Received SS from friends and relatives in the women with preeclampsia were less than those in the healthy PW. This finding is consistent with Moafi et al. (2012),(20). Black et al. (2007) argues that when a woman experiences a risky pregnancy and tries to adapt to her stresses, SS becomes a critical variable (24).

SS induces its positive effect from different pathways on the outcomes of pregnancy. There was a negative relationship between SS and stress and a positive correlation between SS and adaptation. Ditzen et al. (2008) found that high SS was coincident with a decrease in blood cortisol level and attenuation of anxiety in return (40). SS functions as a defense line against stressful events of life and provides the individual with the necessary coping skills to face the stresses (41).

Moreover, SS might have a positive effect on cardiovascular health against life stresses. Heard et al. (2011) found a significant relationship between PS and high BP and that the stress and hypertension can be controlled through adaptation strategies (42). Hypertension decreases with an increase in SS (29). As a result, pregnancy stress and low SS probably increase the risk of preeclampsia $(21,43)$. Iranzade et al. (2014) showed that stress in PW with low SS was significantly high (44).

The findings indicated a significant difference in PS by PW with and without preeclampsia so that women with preeclampsia experienced a higher level of stress comparing with women without preeclampsia. Moafi et al. (2013) found that there was a significant

DOI: http://dx.doi.org/10.4314/ejhs.v29i3.9 
difference between $\mathrm{PW}$ with and without preeclampsia in terms of stress (20). Shampsi et al. (2010) reported that women with preeclampsia experienced a higher level of stress (21). Vianna et al. (2011) reported a positive relationship between stress and preeclampsia (45). In addition to its effect on preeclampsia, stress is effective in severity of a disease. Black et al. (2007) mentioned that the group with severe preeclampsia experienced a higher level of stress compared with the group with mild preeclampsia, and the difference was significant (24).

In another study, a significant relationship between PS and development of preeclampsia was reported $(p=0.008)(22)$. Leaners et al. (2007) found that people with BP disorder experienced a higher level of stress compared with the control group (38.6 vs. 17.8), and the difference was bigger in the group of women with preeclampsia (40 vs. 17.8). Moreover, the HELLP syndrome group also experienced a higher level of stress compared with the control group (40.2 vs. 17.8). Mental stress increases by 1.6 times during pregnancy and increases the risk of BP disorder (23).

Another study on PS during pregnancy showed that pregnancy increased the risk of preeclampsia by $32 \%$ so that a five-points increase in the mean score of stress resulted in 1.32 points increase in the risk of preeclampsia (21).

Hajikhani et al. (2017) found a relationship between stress and BP disorder, which is consistent with our study (19). Nicell et al. (1989) and Vollbregt et al. (2008) reported that stress level was not correlated with increase in the risk of preeclampsia and pregnancy hypertension (46-47). The inconsistency might be due to differences in study populations so that only women who had their first experience of pregnancy took part in their study. Moreover, pregnancy term of the participant on average was 15.6 weeks, and the women with preeclampsia (31.6 \pm 5) were older on average than the women without preeclampsia $(29.8 \pm 5)$. Prevalences of preeclampsia and pregnancy hypertension in the study population were relatively low (3.5-4.4\%); in addition, pregnancy $\mathrm{BP}$ in the study population was relatively low (3.5$4.4 \%$ ) (40). Nicell et al. (1989) reported that women with a high level of stress are more probable to be hospitalized and ask for medical leave due to early uterine contraction. Physical and mental rest might attenuate BP in women experiencing a high level of stress in their lives. Nicell et al. (1989) studied a smaller group of subjects compared with other studies. Another reason for the inconsistent results can be the different data gathering tools as Nicell et al. (1989) used a researcher designed questionnaire (47). Cohen's validated and reliable scale of stress was used in this study (47).

As to the advantages of the study, it is notable that the subjects were selected from different hospitals and the process of selecting and matching the participants with and without preeclampsia from each hospital was random.

In terms of the limitations of the study, the probable effect of individual differences on the PS and $\mathrm{SS}$ is notable. The authors made their best to control this effect through the random selection process. Another limitation was that the level of stress was measured through self-statement and no clinical confirmation was used in this regard.

Pregnant women suffering from preeclampsia perceived more stress and less SS compared with healthy PW. Preeclampsia is characterized with dangerous side effects for the mother and the infant, and it is necessary to screen PW in terms of the risk factors of the disease. Moreover, WHO has emphasized the relationship between the social mental factors and the disease, while there is lack of information in this area. In light of these, stress level screening program for PW and promoting methods to attenuate stress in these women are essential. Moreover, given the effectiveness of SS in attenuating stress, there is a need for developing approaches to increase the support for PW especially the support by mothers-in-law.

\section{ACKNOWLEDGEMENTS}

The article is part of an MSc dissertation in general psychology under ethics code 19220705961021, the Islamic Azad University, Kermanshah Unit. The authors wish to express their gratitude to all the officials of the university and HazratMasoume, Motazedi, and Imam Reza hospital for their supports.

\section{REFERENCES}

1. Golboni F, Heydarpour S, Taghizadeh Z, Kazemnezhad A. Predictive value of plasma hematocrit level in early diagnosis of preeclampsia. EMHJ, 2011; 17(10):744-748.

2. Mol BWJ, Roberts CT, Thangaratinam S, Magee LA, de Groot CJM, Hofmeyr GJ. Pre-eclampsia. Lancet, 2016; 5(387):999.

3. American College of Obstetricians and Gynecologists, Task Force on Hypertension in Pregnancy. Hypertension in pregnancy. Report of the American college of obstetricians and

DOI: http://dx.doi.org/10.4314/ejhs.v29i3.9 
gynecologists' task force on hypertension inpregnancy. Obstet Gynecol. 2013 Nov;122(5):1122-31.

4. Xiaoling Ma, Jinping Li, Brian Brost, Wenjun Cheng, Shi-Wen Jiang. Decreased Expression and DNA Methylation Levels of GATAD1 in PreeclampticPlacentas.Cell Signal. 2014 May; 26(5): 959-967.

5. Rana S, Hacker MR, Modest AM et al. Circulating angiogenic factors and riskof adverse maternal perinatal outcomes in twin pregnancies with suspected preeclampsia. Hypertension. 2012 Aug; 60(2):451-8.

6. Nehbandani S, Koochakzai M, Mirzaee F, Moghimi F. Prevalence of preeclampsia and its maternal and fetal complications in women referring to Amiralmomenin. Hospital of Zabol in 2014-2015. J Birjand Univ Med Sci. 2018, 24(4): 306-312.

7. Rajaee M, Nikuei $P$, Nejatizadeh $A$ et al. Prevalence of Preeclampsia in Hormozgan Province. Hormozgan Medical Journal, 2014;18(6):460-465.

8. Cunningham F, Leveno K, Bloom S, Spong CY, Dashe J.Williams obstetrics. $24^{\text {th }}$ ed. New York: McGrawhill, 2014.

9. Lowdermilk OL, Perry SE, Cashion MC, Alden KR. Study Guide For maternity \& women's Health care. 11th ed. Elseviey Health Sciences; 2015.

10. Canoy D, Cairns BJ, Balkwill A et al. Million Women Study Collaborators. Hypertension in pregnancy and risk of coronary heart disease and stroke: A prospective study in a large UK cohort. Int J Cardiol. 2016 Nov, 1 (222):1012.

11. Kestenbaum B, Seliger SL, Easterling TR et al.Cardiovasculr and thromboembolic events following hypertensive pregnancy. Am J Kidney Dis, 2003; 42(5):982-9.

12. Amirian T, Rahgozar S, Shahshahan Z. Preeclampsia in a Cellular and Molecular View. J Isfahan Med Sch, 2013; 31(234):565-80.

13. World health organization. A Conceptual Frame work for Action on the Social Determinants of Health, Geneva, WHO; 2010.

14. Nikpour S, Kashani ZA, Mokhtarshahi MS, Parsay S, Nooritajer M, Haghani H. Study of the correlation of the consumption of vitamin $\mathrm{C}$-rich foods with preeclampsia and eclampsia in women rReferred to ShahidAkbarabadi Hospital in Tehran. $J$ Iran Univ Med Sci, 2007;54(14):179-91.

15. Fortner RT. Modifiable risk factors for hypertensive disorders of pregnancy among latina women [Dissertation]. Massachusetts:University of Massachusetts Amherst In Partial Fulfilment;2009.

16. Talley P, Heitkemper M, Chicz-Demet A, Sandman CA. Male violence, stress, and neuroendocrine parameters in pregnancy: a pilot study. Biol Res Nurs, 2006; 7(3):222.

17. Norhayati M, Hazlinn N, Asrene A, Emilin W. Magnitude and risk factors for postpartum symptoms: A Literature review. J Affect Disord, 2015; 175: 34-52.

18. Stark MA, Brinkley RL.The relationship between perceived stress and health-promoting behaviors in high-risk pregnancy. J Perinat Neonatal Nurs, 2007 Oct-Dec;21(4):307-14.

19. Haji Khani N, Ozgoli G, Theaghi pour, HamzehGradeshi $Z$, The relationship between mental stress and Hypertensive disorder during pregnancy: A review article. School of disorders during pregnancy: A review article. School of Nursing and midwifery, ShahidBeheshtiUniversity of Medical Science, Tehran, Iran, 2017; 20(7):61-70.

20. Moafi F, Dolatian M, Keshavarz Z, AlaviMajd H, Dejman M. Association between social support and maternal stress with preeclampsia. Soc Welfare Quart, 2013; 13(48):151-70.

21. Shamsi U, Hatcher J, Shamsi A, Zuberi N, Qadri $\mathrm{Z}$, Saleem S. A multicentre matched case control study of risk factors for preeclampsia in healthy women in Pakistan. BMC Womens Health, 2010; 10:14.

22. Abedi M, Saboori E, Rabiei pour S, Rasoli J. the relationship between stress in pregnancy, and pregnancy outcomes: A longitudinal study. Urmia Nurs midwifery fac, 2017; 14(12): 964981.

23. Leaners B, Neumaier-Wagner P, Kuse S, Stiller R, Rath W. Emotional stress and the risk to develop hypertensive diseases in pregnancy. Hypertens Pregnancy, 2007; 26(2):211-26.

24. Black KD. Stress, symptoms, self-monitoring confidence, well-being, and social support in the progression of preeclampsia/gestational hypertension. J Obstet Gynecol Neonatal Nurs, 2007; 36(5):419-29.

25. Miler Lm. The interrelationship between social support and posttrauma symptom in the aftermath of a server motor vehicle accident, state university of network; 2007.

26. Croezen S, Picavet HS, Haveman-Nies A, Verschuren WM, de Groot LC, van't Veer P. Do positive or negative experiences of social support relate to current and future health?

DOI: http://dx.doi.org/10.4314/ejhs.v29i3.9 
Results from the Doetinchem Cohort Study. BMC Public Health, 2012 Jan 21;12:65.

27. Heydarpour S, Keshavarz Z, Bakhtiari M. Factors affecting adaptation to the role of motherhood in mothers of preterm infants admitted to the neonatal intensive care unit: A qualitative study. J AdvNurs, 2017 Jan;73(1):138-148.

28. Parsaierad E, Amir- Ali Akbari S, Mashak R. Comparison of insomnia, sleepness, and social support in depressed and non-depressed pregnant women. social Psychol, 2010; 5(17):19-34.

29. Bell CN, Thorpe RJ, Laveist TA. Race Ethnicity and hypertension: the role of social support. $\mathrm{Am}$ J Hypertens, 2010; 23(5): 534-540.

30. Ganster DC, Victor B. The impact of social support on mental and physical health. Br J Med Psychol, 1988; 61(1):17-36.

31. Vaux A, Phillips J, Holly L, Thomson B, Williams D, Stewart D. The social support appraisals (SS-A) scale: studies of reliability and validity. Am J Community Psychol, 1986; 14(2):195-218.

32. Alan V, Jeffrey PH, Lori H, Brian T, Deirdre W, Doreen S. The Social Support Appraisals (SS-A) scale: Studies of reliability and validity. $\mathrm{Am} \mathrm{J}$ Community Psychol, 1986; 14(2): 195-218.

33. Nasseh M, Ghazinour M, Joghataei MT, Nojomi M, Richter J. A Persian Version of the Social Support Questionnaire (SSQ). Soc. Welf. $Q$ 2011, 11(41): 251-266.

34. Ebrahimi-ghavam S. Validity of locus of control, self-esteem and social support. Tehran: Islamic Azad University of Tehran, Department of Psychology; 1992.

35. Rashedi V, Rezaei M, Gharib M, Nabavi SH. Social support for the elderly: Comparison between home and nursing home. Journal of North Khorasan University of Medical Sciences Summer2013;5(2): 351-356.

36. Khabaz R, Asadi Z. The relationship between perceived social support, psychological hardiness and family communication patterns with quality of life among patients with type II diabetes. J Diabetes Nurs, 2011; 3(2): 53-65.

37. Cohen S, Williamson G. Perceived stress in a probability sample of the United States. In: Spacapan S, Oskamp S (editors), The social psychology of health, Newbury Park, Sage Publishing (1988).
38. Leung D, Lam T, Chan S. Three versions of perceived stress scale: validation in a sample of Chinese cardiac patients who smoke. $B M C$ public Health, 2010; 10(1):513.

39. Maroufizadeh S, Zareiyan A, Sigari N. Psychometric properties of the 14, 10 and 4-item "Perceived Stress Scale" among asthmatic patients in Iran. Payesh, 2014; 13: 457-465. 40. Ditzen B, Schimdt S, Strauss B, Nater UM, Ehlert U, Heinrichs M. Adult attachment and social support interact to reduce psychological but not cortisol responses to stress. J Psychosom Res, 2008; 64(5): 479-486.

40. Ajala E, Olorunsaiye D. An evaluative study of the impact of intervention. Strategies of nongovernmental organisations (NGOS) on social wellbeing, economic empowerment and health of the aged in OYO state, Nigeria. IJAAAS, 2009; 5 (2):1-12.

41. Heard E, Whitfield K, Edwards C, Bruce M, Beech B. Mediating effects of social support on the relationship among perceived stress, depression, and hypertension in African Americans. J Natl Med Assoc, 2011; 103(2):116-122.

42. Coussons-Read ME, OkunML, Nettles CD. Psychosocial stress increases inflammatory markers and alters cytokine production across pregnancy. Brain Behav Immun, 2007; 21(3):343-350.

43. Iranzad I, Bani S, Hasanpour SH, Mohammadalizadeh S, Mirghafourvand $M$. Perceived Social Support and Stress among Pregnant Women at Health Centers of IranTabriz. J Caring Sci, 2014, 3(4), 287-295.

44. Vianna P, Bauer ME, Dornfeld D, Chies JA. Distress conditions during pregnancy may lead to preeclampsia by increasing cortisol levels and altering lymphocyte sensitivity to glucocorticoids. Med Hypotheses, 2011; 77(2):188-191.

45. Vollebregt KC, Van der Wal MF, Wolf $H$, Vrijkotte TG, Boer $\mathrm{K}$, Bonsel GJ. Is psychosocial stress in first ongoing pregnancies associated with preeclampsia and gestational hypertension? BJOG, 2008 Apr;115(5):607-15.

46. Nisell H, Larsson G, Wager J. The relation between life stress and hypertensive complications during pregnancy.Acta Obstet Gynecol Scand, 1989; 68(5):423-7. 